\title{
Stress testing credit card portfolios: an application in South Africa
}

Authors:

Yixin SEAH

Mee Chi So ${ }^{1 *}$

Lyn C. THOMAS ${ }^{2}$

Affiliation and Postal address:

Southampton Management School

University of Southampton

Southampton

United Kingdom

SO17 1BJ

Other Contact Details

email: M.So@soton.ac.uk

Tel: +44 (0)2380598964

Fax: +44 (0)23 80597677

2email: L.Thomas@soton.ac.uk

\begin{abstract}
:
Motivated by a real problem, this study aims to develop models to conduct stress testing on credit card portfolios. Two modelling approaches were extended to include the impact of lenders' actions within the model. The first approach was a regression model of the aggregate losses based on economic variables with auto correlations of the errors. The second approach was a set of vintage level models which highlighted the months-on-book effect on credit losses. A case study using the models was described using South African credit card data. In this case the models were used to stress test the credit card portfolio under several economic scenarios.
\end{abstract}

Key words: consumer credit risk; credit card; stress testing; application in banking

${ }^{*}$ Corresponding author 


\section{Introduction}

In recent years, many lenders have conducted stress tests on their credit portfolios in order to assess and estimate the possible loss when there are changes on economic environments. Several reasons have contributed to the importance and popularity of stress tests. The first is the Basel II and III accords which put considerable regulatory weight behind the need to stress test. The other reason of course is the credit turmoil in 2008 which showed how fragile the current financial systems is when there is an economic shock.

There is a wide range of practices to stress test financial products. IMF defines stress tests as "a range of techniques used to assess the vulnerability of a portfolio to major changes in the macroeconomic environment or to exceptional, but plausible events" (Blaschke et al., 2001). One common stress testing approach is to build models of credit losses based on economic conditions and then to apply different future economic scenarios to these models to see the effect on the credit losses. So far most stress testing research has been applied almost exclusively to corporate lending. (Kalirai and Schleicher, 2002; Hoggarth and Whitley, 2003; Varotto, 2011). The recent credit crunch however has shown stress testing on consumer credit portfolios is essential to estimate the impact of the economy on the financial industry and its stability.

In this study, we estimate the credit risk of credit card products in a real-world application setting. A South African credit lender was interested in developing a robust model to examine the impact of macroeconomic factors on the credit risk of its credit card portfolio so that the resulting model could be used for stress testing. Apart from the external economic environment, the lender also recognised that the operating policy used on the portfolio had changed significantly over the time the data was collected.

To allow for these effects, we use two types of models in this study. The first was a regression based model with autocorrelation errors. These models are the main approach to stress testing credit portfolios (Jiménez and Mencía, 2009; Wong et al., 2006; Virolainen, 2004). In these models, default rate is the dependent variable and macroeconomic variable(s) (e.g. GDP, interest rate etc.) is used as explanatory factor(s). The basic regression model without policy effects turned out to be unsatisfactory in that the impact of economic changes on forecasted credit losses was counter intuitive. Hence a hybrid approach was used, taking into consideration the external factors such as management decisions and seasonality as well as the basic model structure. Stress testing was performed on the forecasts using four different economic scenarios to estimate how the portfolio would perform under different economic conditions.

The second was a hazard type model which included the impact of maturity of the credit card on default rates and hence decomposed the portfolio into different vintages. This approach uses the general portfolio performance to map the shape of the months-on-book effect (called the Maturation Curve), which is so important in retail credit. Exogenous, time-based variables such as seasonality, management actions and economic environmental factors were later factored into the Maturation Curve to produce a vintage curve 
(Breeden and Smith, 2002; Breeden, 2007). Although vintage cycles can be applied to many variables (e.g. roll rates, utilization), they are generally difficult to implement accurately, and adjustments must be made for the quality of each vintage (Breeden, 2003). One assumption made when modelling vintages is that though different vintages have different default trajectories, the relative progression of losses through time is stable for all vintages (Hatzius, 2008).

The rest of the paper is organised as follows. We present the detail model formulation of the two approaches in Section 2. The background of this case study will be presented in Section 3. The results of both models are discussed in Section 4. The conclusion is given in the last section.

\section{Methodology}

In this section, we present the methodology of our study. We use two different approaches to estimate the aggregate default rate of credit card portfolios.

\subsection{Regression based aggregate loss model}

In the multi-variate regression modelling approach the default rate at time $\mathrm{t}\left(y_{t}\right)$ is the outcome variable and macroeconomic variables $\left(x_{1 t}, x_{2 t, \ldots,} x_{N t}\right)$ are explanatory variables at time $t$. In this application simple uni-variate regression models were built using different lags (indexed by $l=1,2, \ldots, L$ ) for each variable in turn and the lag with the highest $\mathrm{R}$ squared value (goodness of fit test) was chosen as the appropriate one for that variable. The forward stepwise regression method was then applied using the appropriately lagged version of each variable to produce the simple multivariate model.

Due to the input variables being time variables, there was a possibility of autocorrelation of error terms in the model, meaning that the error of month $t\left(Z_{t}\right)$ could be correlated with the error of month $t-1$. An autocorrelation correction was carried out on the final regression model by adding autocorrelation correction terms. So the overall model therefore was

$$
y_{t}=\sum_{n=1}^{N} \beta_{n} x_{n t}+Z_{t}, \quad t=1, \cdots, T \quad \text { where } \quad Z_{t}=\sum_{l=1}^{L} \rho_{l} Z_{t-l}+\epsilon_{t}
$$

where $\beta_{n}$ and $\rho_{l}$ are regression parameters and autoregressive parameters respectively, and $\epsilon_{t} \sim$ i.i.d. $N\left(0, \sigma^{2}\right)$ is the error term for the white noise. Backward elimination was then applied to remove the lagged error terms with lowest t-values one by one. The Durbin-Watson statistic $(d)$ was also checked for positive or negative autocorrelation. As a rule of thumb, there is no autocorrelation if $d>1.6$ (Brochlebank and Dickey, 2005). 
If it is known that the lender's portfolio management strategies were changed substantially one or more times during the period, dummy variables can be added to (1) to represent each subperiod. We called this the Hybrid model:

$y_{t}=\sum_{n=1}^{N} \beta_{n} x_{n t}+\sum_{i=1}^{K} c_{i} D_{\left[t_{i-1}, t_{i}\right]}(t)+Z_{t}, \quad t=1, \cdots, T \quad$ where $\quad Z_{t}=\sum_{l=1}^{L} \rho_{l} Z_{t-l}+\epsilon_{t}$

where $\mathrm{D}_{[t, \mathrm{~s}]}$ is a dummy binary variable representing the managerial decision from time $t$ to time. We are assuming there are $\mathrm{K}$ different policies implemented with policy $i$ being implemented from $t_{i}$ to $t_{i+1}$ and $c_{i}$ is the corresponding regression parameter The choice of when there are changes in policy is obtained by discussion with the appropriate decision makers within the lending organisation and by checking when policy changes were made.

\subsection{Vintage segmented months-on-book model}

The second approach in this study examines the impact of the maturity of the credit card on the default rate and so segments the portfolio by vintage. A vintage of a credit card account is defined as the starting period of the credit card. A curve y against the months-on-book for different vintages can be plotted (See Figure 9 for illustration). Breeden (2007) proposes that one can model this curve by three factors: maturity, exogenous and vintage quality. We use a similar approach but also include seasonality into the model since it may have impact on the default rate. Therefore, for the segment of the portfolio which started at time $t_{0}$, the default rate at time $t+t_{0}$ (i.e. $t$ periods after the credit facility was made available) is modelled as:

$$
\ln \left(r_{t_{0}}(t)\right)=v_{t_{0}}+m_{t}+s_{\left(t+t_{0}\right) \bmod 12}+e_{t}
$$

where $r_{t_{0}}(t)$ is the rate of default at time $\mathrm{t}$ for vintage $t_{0}, v_{t_{0}}$ is the vintage $t_{0}$ performance, $m_{t}$ is the maturity curve at time $t, s_{\left(t+t_{0}\right) \bmod 12}$ is the seasonality (based on 12 months). The residuals, i.e. $e_{t}$, is caused by the exogenous effects of macroeconomic factors or management actions.

To model this, initially the average months-on-book curve is obtained by first plotting the default rate at time $t$ for each vintage and the average over the curves for different vintages obtained (See Figure 9 for illustration). A maturation curve $\left(m_{t}\right)=\ln (r(t))$ was fitted as closely as possible to the average vintage curve. The resulting maturation curve was a combination of a logistic function and a decay factor (Chapter 4, Breeden 2010), with the following formula: 


$$
A_{1} \times\left\{A_{2}+\left[\frac{A_{3}}{1+\exp \left(\frac{-A_{4} \times\left(t+A_{5}\right)}{A_{6}}\right)}\right]\right\}+A_{7}-\left(\frac{\sqrt{t}}{1000}\right) \times A_{8}
$$

$A_{1}$ to $A_{8}$ were constant values that we can't publish for confidentiality reasons. In this equation, the first part (i.e. $A_{1} \times\left\{A_{2}+\left[\frac{A_{3}}{1+\exp \left(\frac{-A_{4} \times\left(t+A_{5}\right)}{A_{6}}\right)}\right]\right\}$ ) increases with $t$ whereas the second term (i.e. $A_{7}-\left(\frac{\sqrt{t}}{1000}\right) \times$ $A_{8}$ ) decreases with t. One can see the first and second parts are the short term and long term effects on the hazard rate of credit card portfolios respectively. There is an initial rise on hazard rate in the first year since default takes a few months to occur. In the longer term though, the credit card portfolio's hazard rate starts to drop because the riskier borrowers have defaulted. The equation therefore is a combination of both effects. Seasonality was calculated by using the variance from the total average losses for each month. Then, the exogenous effects are estimated in a very similar way to that used for the aggregate regression based approach, namely:

$$
e_{t}=\sum_{n=1}^{N} \beta_{n} x_{n t}+\sum_{i=1}^{K} c_{i} D_{\left[t_{i-1}, t_{i}\right]}(t)+Z_{t}, \quad t=1, \cdots, T \quad \text { where } \quad Z_{t}=\sum_{l=1}^{L} \rho_{l} Z_{t-l}+\epsilon_{t}
$$

where the notations are defined to the same as in (1) and (2). In particular $D_{[t, s]}$ is a dummy binary variable representing the set of portfolio management strategies in place from time $t$ to time $\mathrm{s}$, and we assume there are $K$ different policies implemented during the sample period with policy $i$ being implemented from $t_{i}$ to $t_{i+1}$.

\section{Background to case study}

South Africa is said to have a two-tiered economy; one that is similar to developed countries, and the other which relies on primary infrastructure. Key economic sectors include mining services, manufacturing, energy, transport, tourism and agriculture (South African Government Information, 2008). South Africans have been reaping the rewards of economic growth, as the disposable income of households has been increasing (Figure 1a). However, there has also been an increasing trend in household debt (Figure 1b), and this will have an effect on credit losses. South Africa used to be the world's leading producer of Gold, although its importance has diminished over the years. In terms of employment in South Africa, mining and construction used to be the major employment industries. These 
industries, however, were overtaken by Finance and banking as South Africa's major employer in 2002 (Figure 1c).

[Figure $1 \mathrm{a}, 1 \mathrm{~b}$ and $1 \mathrm{c}$ about here]

Unemployment in South Africa is high, standing at 25.3\% in 2010 (SA StatsOnline, 2010), although this figure would increase to $36 \%$ if those too discouraged to seek work are included. This shows that there is a large difference in unemployment rates between the 'broad' and 'narrow' definitions. The 'Narrow' "unemployed" rate refers to the jobless who were looking for work when the survey was made. The 'broad' definition includes those in the 'narrow' definition and jobless people who were not looking for work during the reference period (Kingdon \& Knight, 2000). In South Africa, official statistics use the 'narrow' definition as the official definition. This large difference in the two rates could explain why unemployment is not traditionally deemed as a key economic indicator in South Africa.

The credit card data used in the case study covers the period from January 2005 to July 2010. Default was defined as accounts which become 90 or more days in arrears. This is identical to the definition in the New Basel Accord. The lender was also interested in Delinquent rate which is defined as

$$
y_{t} \equiv \text { Delinquent rate at time } t=\frac{\text { Total Delinquent Balances at time } t}{\text { Total Balances at time } t} \times 100
$$

A plot (i.e. Figure 2) ${ }^{1}$ of Delinquent Balances and Default rate, which is percentage of accounts that default in a period, show that both exhibit similar trends, both for our choice of default $(3+$ months delinquent) and for $1+, 2+, 4+$ and $5+$ months delinquent. This may be due to the fact that the portfolio is relatively homogenous in terms of credit card limits, so that results are not distorted by differing risk profiles at the very high or very low value ends. Therefore, there was no need to have two separate models for volumes and balances and we use the delinquent rate as our measure of the default rate in this case study.

[Figure 2 about here]

There are some obvious trends in Figure 2 that should be captured by the models created. There is a rapid increase in loss rates from January 2005 to around March 2007, where a slight peak is seen. The loss rates then plateau from July 2007 up till January 2009, peaking around March 2009 before decreasing slightly. These peaks may due to the lack of regulation on consumer credits before March 2006 when the National Credit Act (South Africa Government Gazette, 2006) was introduced by the South Africa

\footnotetext{
${ }^{1}$ For confidentiality reason, in this paper, we do not disclose the actual value of the percentage loss.
} 
government. Prior to the act's implementation, many lenders had signed up new customers. Much of those were risky accounts and the result flowed through in the following years.

The choice of which factors to include in the stress testing model was made based on what was used by other stress testing models, even though, most of these are corporate credit risk models, factors which impact on the South African economy and the availability of the forecasts. The frequency of data chosen depended on the frequency of forecast data of the variable. Thus the following macroeconomic factors of South Africa were studied:

[Table 1 about here]

The quarterly or yearly recorded variables were standardized to monthly observation for the regression. This was done by either fitting a cubic spline or performing nearest neighbour interpolation to fit in the missing data, using the given data as the average of the period. The variables were checked for unusual data (e.g. Missing values, outliers, etc.) and then subjected to the following statistical transformations: Log transform (strictly non-negative variables), square transform (strictly non-negative variables), square-root transform (strictly non-negative variables), and inverse transform. These are the common transformations used to improve linearity between the macroeconomic variables and the dependent variable in the regression. The macroeconomic variables were lagged from a lag of 0 months to a lag of 12 months, so as to allow for the delay in the changes in economic conditions impacting on delinquent rate.

Different economic scenarios were used in the stress testing of the portfolio. Four scenarios were chosen to reflect the impact of different economic and regulatory future on the world, as well as in South Africa. The four scenarios were named "Good", "Moderate", "Bad" and "Worst". The lender provided detailed descriptions of the economic environment under these four scenarios. We are not able to disclose the details for confidentiality reasons, but the names are apt descriptions of the scenarios being simulated.

\section{Results and Analysis}

\subsection{Regression based aggregate loss model}

Initially the regression aggregate loss model was constructed on the assumption that delinquent rate were impacted only by macroeconomic variables. The forward regression approach chose GDP $(+)^{2}$ and Gold inverse $(-)^{3}$ as the explanatory variables each with a lag of 9 months. It is common for GDP to be picked up as a key macroeconomic variable in credit risk analysis (e.g. Altman et al., 2001; Virolainen, 2004;

\footnotetext{
${ }^{2}(+)$ indicates the explanatory variable has a positive sign

${ }^{3}(-)$ indicates the explanatory variable has a negative sign
} 
Bonfim, 2009). Gold has historically been one of South Africa's most valuable exports, and its price is widely used as an economic indicator when modelling South African portfolios. If gold price decreases, the export receipts decrease drastically and this impacts GDP. This model gave a R-squared value of 0.9505, indicating a very good fit. The Pearson correlation between Gold inverse and GDP was 0.72776 $(p<0.05)$, indicating that there was some but not highly significant collinearity between the two variables. White's Test (White, 1980) was used to test for heteroscedasticity of the residuals. This was to ensure homogeneity of variance of residuals, which is an assumption when Ordinary Least Squares Regression is carried out. Since the value of the White's test was 0.3005 , there was insufficient evidence to reject the "null" hypothesis which states the variance of residuals is homogenous.

Autocorrelation correction was then undertaken using the autoregression terms together with the GDP and gold inverse factors. The R-squared value improved to 0.9825 after adding in an autocorrelation correction factors. The Durbin-Watson statistic after autoregression was 1.7283 , indicating that there was no more autocorrelation.

[Figure 3 about here]

The resulting equation gave the forecast a very sharp increase in losses from mid-2010 onwards (Figure 3), which would probably not occur (and with hind sight has not occurred). It also meant that the delinquent rate was forecast to be least under the worst scenario and highest under the good scenario which is completely counterintuitive. Part of the difficulty seemed to be caused by the forecasted GDP values. The GDP data was hence re-splined to make the forecasts smoother. The new spline was used both actual data and model forecasts, instead of only the actual data as was done with the old GDP spline. Having these revised data values slightly changed the shape of the curve and though

[Figure 4 about here]

the GDP values using the new spline approach led to a model with lower R squared 0.9310. After adding the autocorrelation correction, the model's R squared was 0.9789 . The fit of the new regression was still considered good. The results are shown in Figure 4. The graphs of Gold Inverse and GDP can be seen below.

[Figures $5 \mathrm{a}$ and $5 \mathrm{~b}$ about here]

Figures $5 \mathrm{a}$ and $5 \mathrm{~b}$ show the actual and forecasted gold price and GDP and from these it is clear the forecasts from the model of balanced losses will depend much more on the GDP than the Inversed Gold Price, since the latter does not vary much over time.

While a good R squared value was obtained for this model, the forecast did not make much intuitive business sense. GDP is usually negatively correlated to delinquent rate because as the economy worsens, customers tend to have a harder time keeping up with payments due to unemployment, while in this 
model it has a positive sign. Moreover although one could make a case for the rate of delinquent rate being high in good time and lower in bad times - more consumers take out loans in good times, whereas in poor economic situations consumers spend and borrow less - it is normally accepted that the loss rate should be higher in the poor economic conditions than in the good economic scenario. That is not the case here. This showed that building a model based only on economic factors was not reasonable and there was a need to create a second hybrid aggregate model.

\subsection{Hybrid regression based aggregate model}

A second regression based aggregate model was constructed, which took into account the impact of company decisions. Figure 6 below shows a comparison of the delinquency rates in terms of both balances and volumes, and when the major changes were made to portfolio management strategies over the period.

[Figure 6 about here]

The lender identified four different strategies that had been in place over the period 2004 to 2010 . Initially, from July 2005 to May 2007 there was a fairly lax approach both to whom was given credit cards initially and also to the way accounts in arrears was being chased up. Slightly higher standards were then applied to applications during the second period, June 2007 to December 2008, and an even tighter acceptance policy was introduced from January 2008 until June 2009. This is now considered to be the normal policy appropriate for a "steady state". Finally from July 2009 onwards a much stricter policy was applied to delinquent accounts. As the strategy used in the third period was considered the norm, the changes in delinquent rate in this period losses were assumed to be due to macroeconomic factors only. So regression models were fitted to the data in this period. The best fit was obtained using GDP (-ve sign) and Prime Interest Rate (+ve sign) both with lags of 9 months. The newly splined GDP was used in this regression, while the Prime Rate forecast was interpolated using Nearest Neighbour Interpolation. The forecasted loss is presented in Figure 7.

[Figure 7 about here]

The corresponding R squared value was 0.9492 for 3+ month overdue losses. Using the White's Test, we found that the collinearity between GDP and Prime Interest rate was 0.605 , indicating that there was no significant collinearity between the variables (White, 1980). White's test was 0.1967 and thus there was insufficient evidence to reject the null hypothesis.

The regression equation shows an inverse relationship between losses and GDP, indicating that as GDP improves, losses would decrease. Likewise, when Prime interest rates increases, the portfolio typically shows higher losses. The Prime Rate in South Africa is the most common benchmark for setting variable interest rates (South African Reserve Bank, 2009) and very little fixed rate lending is done. These are 
much more reasonable relationships between the dependent and independent variables. Moreover when one applies the different scenarios to this model, the ordering of loss rates is what might be expected with the highest loss rates in the worst scenario and the lowest in the good scenario.

For these forecasts one has to ask what the most likely management actions are under the various scenarios, since they will affect the default rates. We consulted an experienced risk analyst in the company to determine which policy might be used for each economic scenario and the associated delinquency rates. We applied these strategies to the forecast. So this hybrid model is more intuitive and takes into consideration the impact of different portfolio management strategies over the period. Figure 8a shows the timings of the different policies that were suggested for the "moderate" scenario.

[Figure $8 \mathrm{a}$ and $8 \mathrm{~b}$ about here]

This forecast as shown in Figure 8b was a reasonable one, given that the "Moderate" loss forecast (the economic base case scenario) hovers around the same rate as the lenders' other credit card portfolios.

\subsection{Vintage segmented months-on-book model}

This second type of model was based on the dual time dynamics approach of Breeden (2007). In this model, the changes in delinquency rates over that period were assumed to be the product of the impact of the maturity of the card (i.e. month-on-book), the vintage of the card (when they were first opened) and a remaining factor which should be explained by the economic situation. Following Breeden (2007) and the analysis done earlier in this paper on the aggregate model, one realises that this term should include dummy variables describing changes in the lender's policy as well as the economic variables. There is though a difference between the lender's policy changes considered in this approach and that in the regression based aggregate approach. In this model, changes to accept/reject criteria for new accounts are already captured by the vintage effect, and only changes to account management/collections strategies should be considered (i.e. those applied after the account is opened). In this case such changes were in the way accounts in arrears were dealt with. In the aggregate model the changes in policy cover both changes in the initial acceptance policy and in the subsequent operating policy.

The model was built using accounts opened after January 2008 because the acceptance policy for accounts opened before then was considered to be far too lax to be used in future. Initially the average maturation curve was calculated by plotting the maturation curve for each vintage and taking the average values. Figure 9 shows how close this average maturation curve is to the maturation curves for the different vintages. A logistic function was chosen to model the average maturation both because the average curve showed a sigmoidal increase in losses initially and because logistic functions have been used to model probability of defaults by other authors (Jimenez and Saurina, 2006). Due to the lack of data, the maturation curve was only constructed up to 29 months. The Maturation Curve shows that delinquency rates tend to peak after about 13 months-on-book. 
Having found the maturation curve $m_{t}$ we then use (3) to calculate $\mathrm{v}_{\mathrm{t}}$ and $\mathrm{e}_{\mathrm{t}}$ by using partial least squares. The standard dual time dynamic model was extended by including a seasonality term $\mathrm{s}_{\mathrm{t}}$ into the formula for the balance loss rate (3). The seasonality impact is shown in Figure 10, which shows delinquency rates by month for each of the years.

[Figure 10 about here]

From the seasonality plot, it can be seen that the debts usually start accumulating during the holiday season (Christmas and New Year), leading to a peak in delinquency rates in April.

The $e_{t}$ term in the decomposition of the rate of delinquent rate was initially modelled as a function of only the economic variables. The best $\mathrm{R}$ squared value was 0.635 , when stepwise regression simply chose GDP with a lag of 9 months. Dummy variables to describe the changes in lenders policy were also introduced. In this case only two dummy variables were needed to describe the changes in the policy concerning accounts in arrears.

[Figure 11 about here]

Figure 11 shows the actual vintage performance, and forecasts of delinquency rates both with and without the dummy variables. The introduction of the policy changes has dropped the balance loss rate significantly though we are using the rather more restrictive arrears management policy that was brought in July 09 all through the forecast period for all the scenarios. It is difficult to test how well a stress test model forecasts unless one can subsequently do backtesting sometime in the future. Even then one can only test it using the scenario that actually occurred allowing for the lender policy that was actually pursued. However one can use expert judgment of risk analysts within the organisation to determine which set of forecasts they feel is more likely. After discussing with some risk analysts in the organisation, there was a unanimous view that the forecasts including the dummies for the lender's policies were the more acceptable.

\section{Conclusion and Future Directions}

Two regression based aggregate models and one dual time dynamics model were constructed and used for stress testing a South African credit card portfolio. Macroeconomic data was obtained on the South African economy. The critical finding was that the forecasts needed for stress testing seemed much more appropriate when the lender's policy was included in the models.

The first Aggregate Model was a purely econometric one. Although the regression fit was good, the forecast did not make business sense. Therefore, there was a need to create a second Hybrid Aggregate Model that included dummy variables to mimic management strategies and these produced a model 
which made much more business sense. The last model was a Hybrid Vintage Model that incorporated the use of macroeconomic variables, dummy variables and seasonality trends. This third model provided another dimension for analysis, because it forecasted the default rate by vintage. Therefore, it gives a useful insight to understand the quality of a particular vintage. Subsequently, Lenders can use the analysis to make future collection or account management decisions, but assumptions have to be made about the quality of new vintages going forward.

Although one was able to fit the current data well with an economic variable only regression model, the forecasts from the model did not make sense, which shows it is not enough just to find the model that best fits the current data. The introduction of dummy variables to reflect lender's changes in policy improved both models considerably in terms of making more sensible forecasts. The results therefore show that management actions are likely to affect or even dominate the effects of changes in the economic environment. 'As discussed before, the environmental framework (e.g. the South Africa Credit Act in this paper) should also be considered. However introducing these extra factors does mean that for forecasting one has to decide what future actions the lenders will undertake. These are likely to be different for the different future scenarios. However this recognition that lenders will respond to changes in future economic conditions makes these models more flexible and realistic.

This study showed that GDP is a strong indicator of credit risk for South Africa, being a key indicator for all the models. However, it should be noted that this may not always be the case because, as in the case of Indonesia in 1996, economic expansion could be fuelled by exports more than domestic consumer expenditure (Breeden and Thomas, 2007). Therefore, GDP may not always reflect the actual situations faced by consumers in the country.

Some of the difficulties in this were the lack of data and forecasts. Some economic data was only recorded annually, and so it was necessary to interpolate this data to obtain monthly values if one wanted to build a model with monthly time periods. Adding dummy variables to mimic management decisions was also difficult due to the lack of experience of the management team of what were the likely impacts of these changes and how long before they would become apparent in the balance loss rates. The approach taken in adding dummy variables was partly analytical and partly intuitive, using benchmarking to other portfolios.

Due to the number of policy changes that had taken place during the sample period, there was insufficient data for out-of-time sampling. This would be ideal if there was more data to perform out-of-time testing, which would be a better measure than the in-time fitting used in this study. However there are many situations in financial organisations where changes in the portfolio mix and new lender policies being implemented mean that there is insufficient data to perform out of sample testing on an appropriate sample. In that case one has to use expert judgment about whether the forecasts are reasonable, which is what was done here. 
One area of potential research would be using Survival Analysis to do the vintage model. This could be done by incorporating different factors in a Cox Proportional Hazard model, as done by (Malik and Thomas, 2010). Using a Cox proportional hazard model would eliminate the need of finding a suitable form for the maturation curve.

\section{Acknowledgements}

The authors want to thanks the anonymous financial institute which supported this work. Without their help, the work could not have been undertaken. The authors would also like to thanks all three anonymous referees who provide insightful recommendations and suggestions. Any mistakes are solely ours.

\section{References}

Altman E I, Resti A and Sironi A (2001). Analysing and explaining default recovery rates. Report submitted to the International Swaps and Derivatives Association, London.

Blaschke W, Jones M T, Majnoni G. and Martinez Peria S (2001). Stress testing of financial systems: An overview of issues, methodologies and FSAP experiences. International Monetary Fund Working paper 88: Basel.

Bonfim D (2009). Credit risk drivers: evaluating the contribution of firm level information and of macroeconomic dynamics. Journal of Banking \& Finance 2: 191-309.

Breeden J L (2003). Portfolio Forecasting Tools: What You Need to Know. RMA Journal Sept:1-11.

Breeden J L (2007). Modeling data with multiple time dimensions. Computational Statistics \& Data Analysis 51: 4761-4785.

Breeden J L (2010). Reinventing Retail Lending Analytics, Risk Books, London.

Breeden J L and Smith M A (2002). Predicting Credit Score Calibration through Economic Events. Presentation in Credit Risk Modeling and Decisioning, Wharton, University of Pennsylvania: Philadelphia.

Breeden J L and Thomas L (2007). A Common Framework for Stress Testing Retail Portfolios across Countries. CORMSIS Working paper, University of Southampton: Southampton. 
Brocklebank J C and Dickey D A (2005). SAS for forecasting time series 2nd edition. SAS Institute Inc.: North Carolina.

Hatzius J (2008). Beyond Leveraged Losses: The Balance Sheet Effects of the Home Price Downturn. In: Elmendorf D W, Mankiw N G and Summers L H (eds). Brooking Papers on Economic Activity. The Brookings Institution: Washington D.C., pp.195-227.

Hoggarth G and Whitley J (2003). Assessing the strength of UK banks through macroeconomic stress tests. Bank of England Financial Stability Review, London.

Jiménez G and Saurina J (2006). Credit cycles, credit risk and prudential regulation. International Journal of Central Banking June: 65-98.

Kalirai H and Schleicher M (2002). Macroeconomic stress testing: Preliminary evidence for Austria. Austrian National Bank Financial stability report 3: Austria.

Kingdon G and Knight J (2000). Are searching and non-searching unemployment distinct states when unemployment is high? The case of South Africa. The Centre for the Study of African Economies Working Paper Series: South Africa

Malik M and Thomas L (2010). Modelling credit risk of portfolio of consumer loans. Journal of the Operational Research Society 61: 411-420

SA StatsOnline (2010). StatsOnline, Retrieved August 6, 2010, from Latest Key Indicators: http://www.statssa.gov.za/keyindicators/keyindicators.asp

South Africa Government Gazette (2006). National creidt act, 2005, South Africa Government Gazette, South Africa 489

South African Government Information (2008). South Africa at a glance. Retrieved 07 09, 2010, from Government communications: http://www.info.gov.za/aboutsa/glance.htm

South African Reserve Bank (2009). The role of the Prime Rate and the Prime-repurchase rate spread in the South African banking system. South African Reserve Bank, The Banking Association: South Africa 
Varotto S (2011). Stress testing credit risk: The great depression scenario. Journal of Banking \& Finance advance online publication 8 October, doi.org/10.1016/j.jbankfin.2011.10.001.

Virolainen K (2004). Macro stress testing with a macroeconomic credit risk model for Finland. Bank of Finland discussion paper, No. 18

White $\mathrm{H}$ (1980). A heteroskedasticity-consistent covariance matrix estimator and a direct test for heteroskedasticity, Econometrica 48: 817-838

Wong J, Choi K F and Fong T (2006). A framework for macro stress testing the credit risk of banks in Hong Kong. Hong Kong Monetary Authority December: Hong Kong 


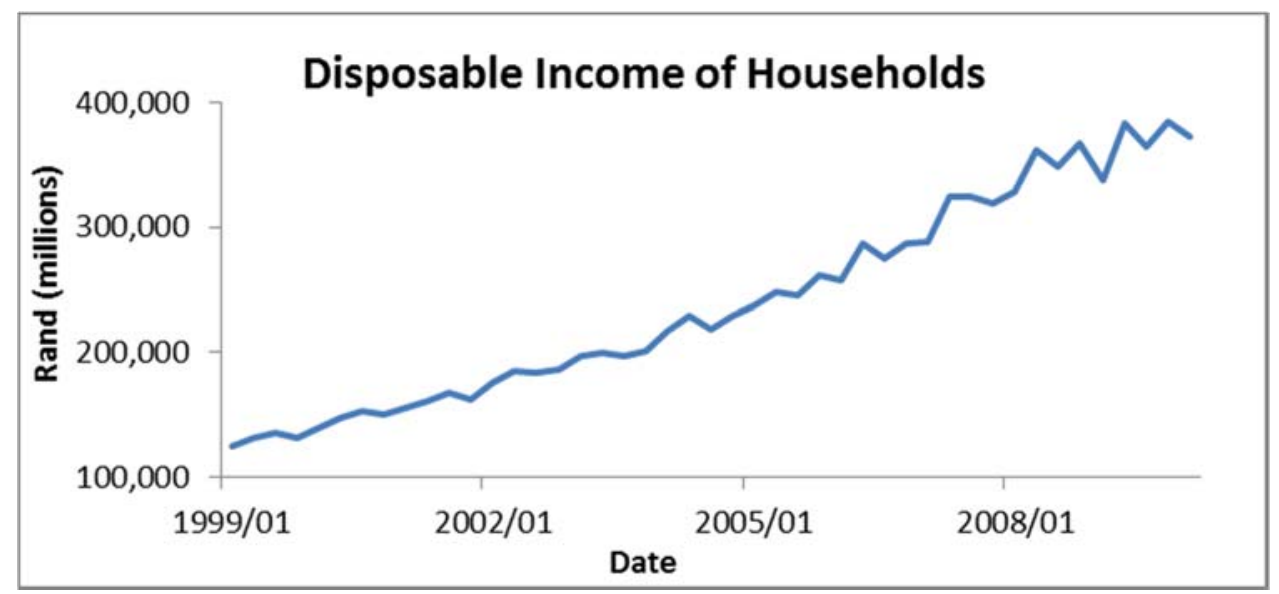

Figure 1a: Disposable Income of Households

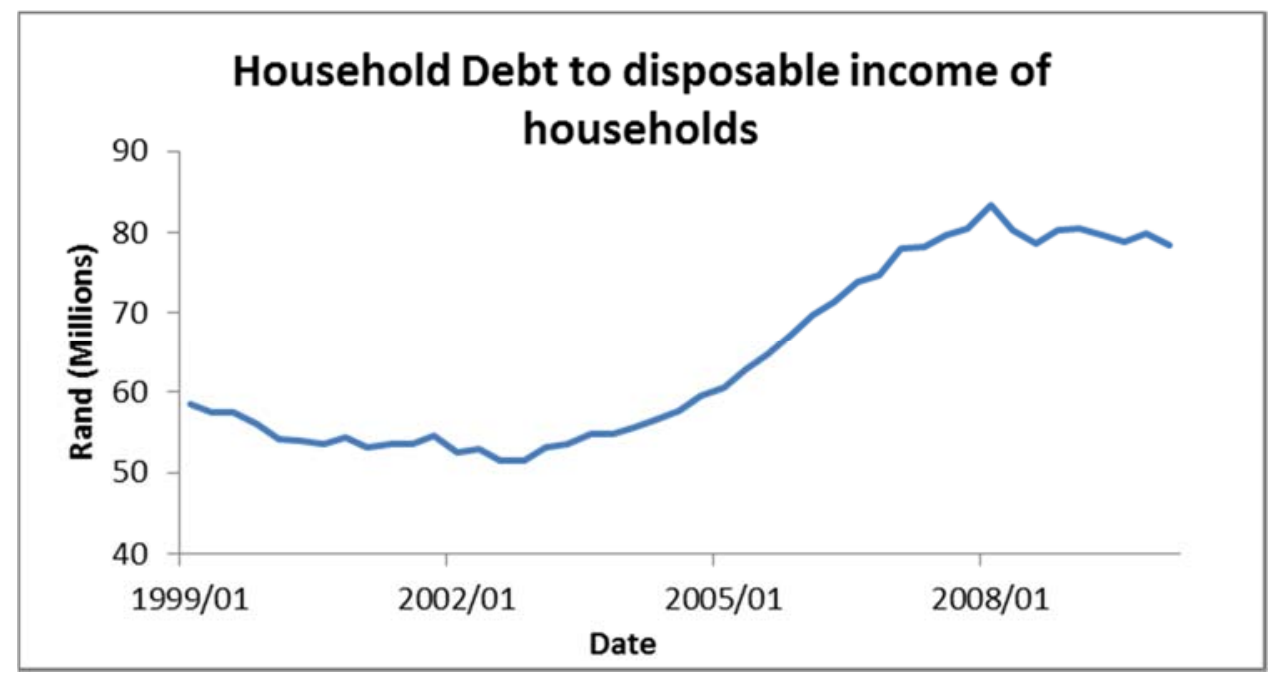

Figure 1b: Household Debt to Disposable Income

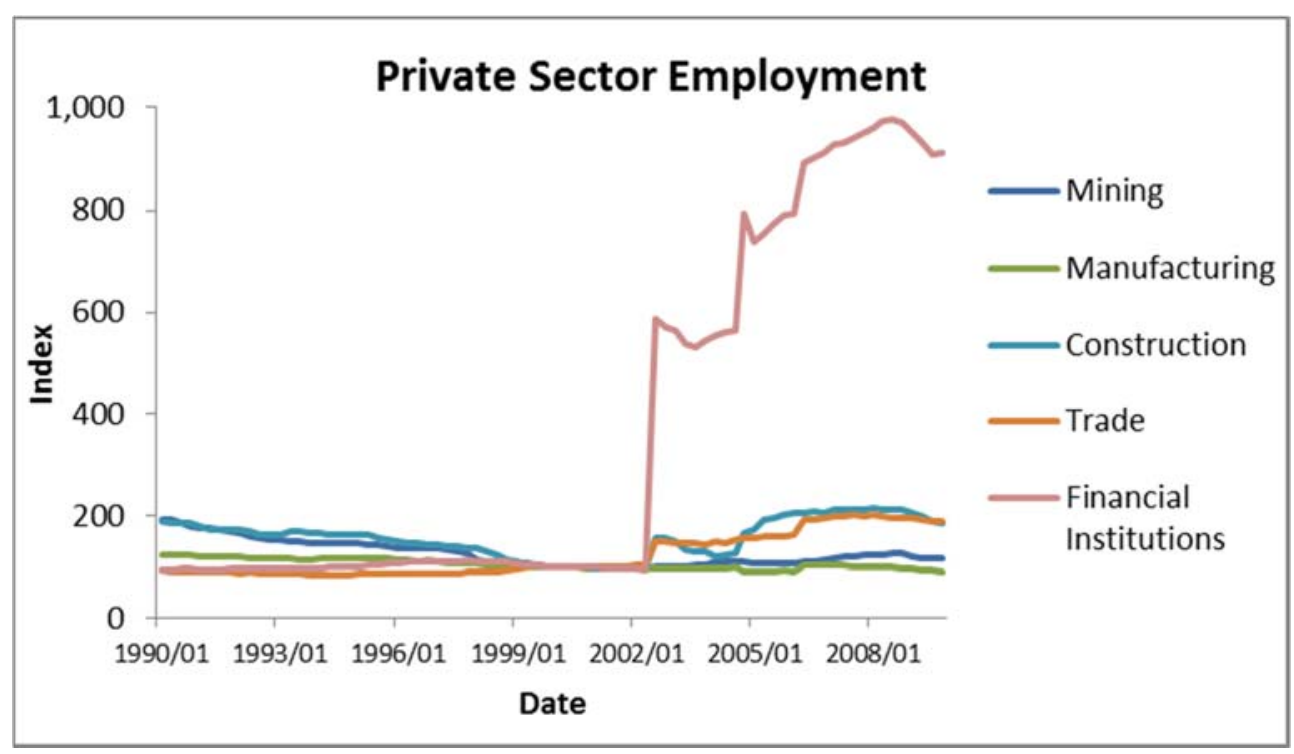

Figure 1c: Employment breakdown 


\begin{tabular}{|c|c|c|c|}
\hline Factor & Frequency & $\begin{array}{l}\text { Unit of } \\
\text { Measure }\end{array}$ & Comments \\
\hline $\mathrm{CPI}$ & Monthly & Percentage & $\begin{array}{l}\text { Consumer Price Index excluding } \\
\text { food and non-alcoholic } \\
\text { beverages and petrol }\end{array}$ \\
\hline $\begin{array}{l}\text { Inter-bank Long term } \\
\text { Interest Rates (JIBAR) }\end{array}$ & Weekly & Percentage & $\begin{array}{l}3 \text { month JIBAR- Johannesburg } \\
\text { Interbank Agreed Rate. This gives } \\
\text { long term bond yields }\end{array}$ \\
\hline Interest Rate (Prime) & Monthly & Percentage & Prime Overdraft Rate \\
\hline Gold Price & Monthly & US dollar & London Gold Price in US dollars \\
\hline GDP YoY growth & Yearly & Percentage & $\begin{array}{l}\text { Gross Domestic Product at } \\
\text { market prices }\end{array}$ \\
\hline GDE YoY growth & Yearly & Percentage & Gross Domestic Expenditure \\
\hline $\begin{array}{l}\text { Consumption } \\
\text { expenditure by } \\
\text { households }\end{array}$ & Yearly & Percentage & $\begin{array}{l}\text { Total expenditure, 1-Term \% } \\
\text { change }\end{array}$ \\
\hline PPI & Monthly & Percentage & $\begin{array}{l}\text { Total producer prices of exported } \\
\text { commodities }\end{array}$ \\
\hline $\begin{array}{l}\text { Current Account } \\
\text { Balance }\end{array}$ & Quarterly & Percentage & $\begin{array}{l}\text { Ratio of current account balance } \\
\text { to GDP }\end{array}$ \\
\hline Exports & Yearly & Percentage & $\begin{array}{l}\text { Growth of exports of goods and } \\
\text { services }\end{array}$ \\
\hline
\end{tabular}

Table 1: Macroeconomic Factors

Notes: We did not have enough time to include more macroeconomic variables in the analysis. For future reference, we recommend researchers/analysts could include the following variables as well: a) local stock market indices (e.g. the JSE all share); b) other commodities, such as platinum; c) the Rand gold price. 


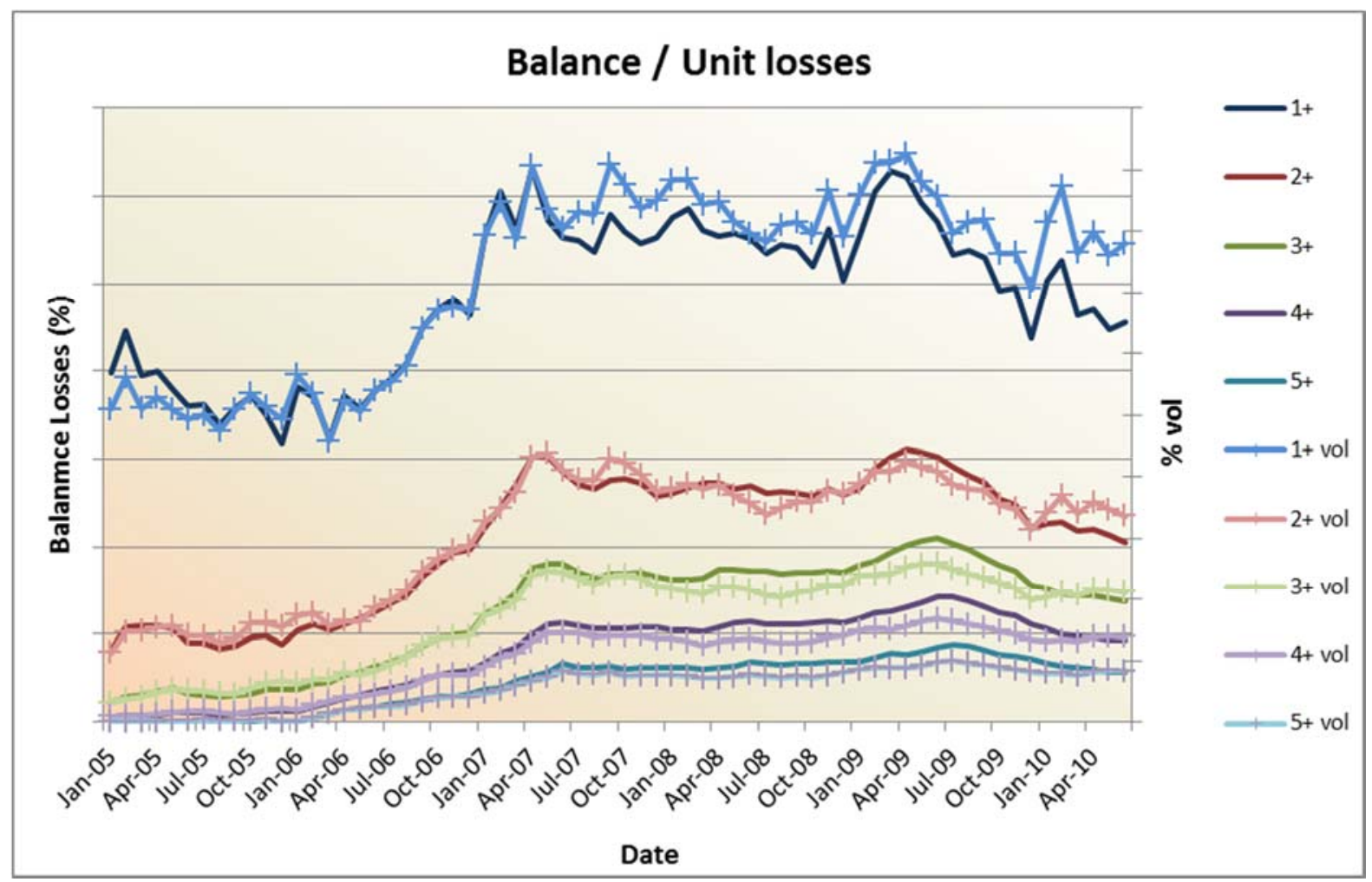

Figure 2: Balance losses (\%) and \% of default accounts

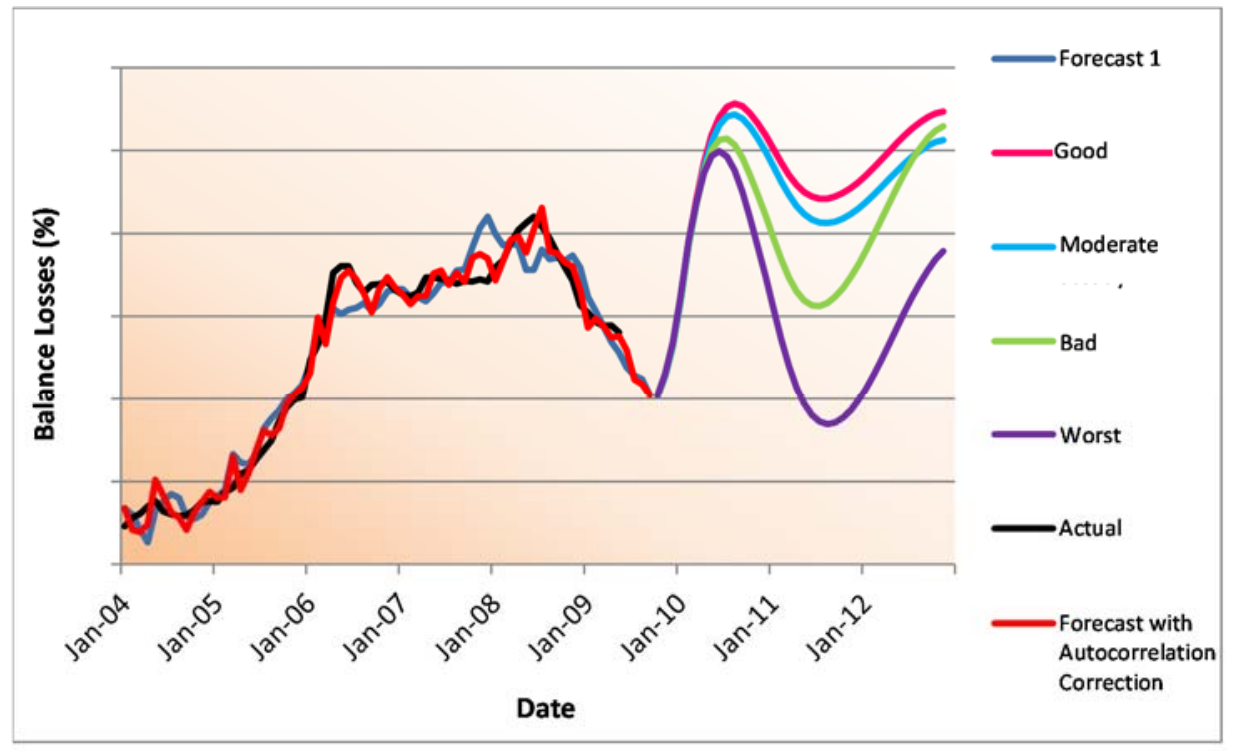

Figure 3: Basic regression Model with old GDP spline 


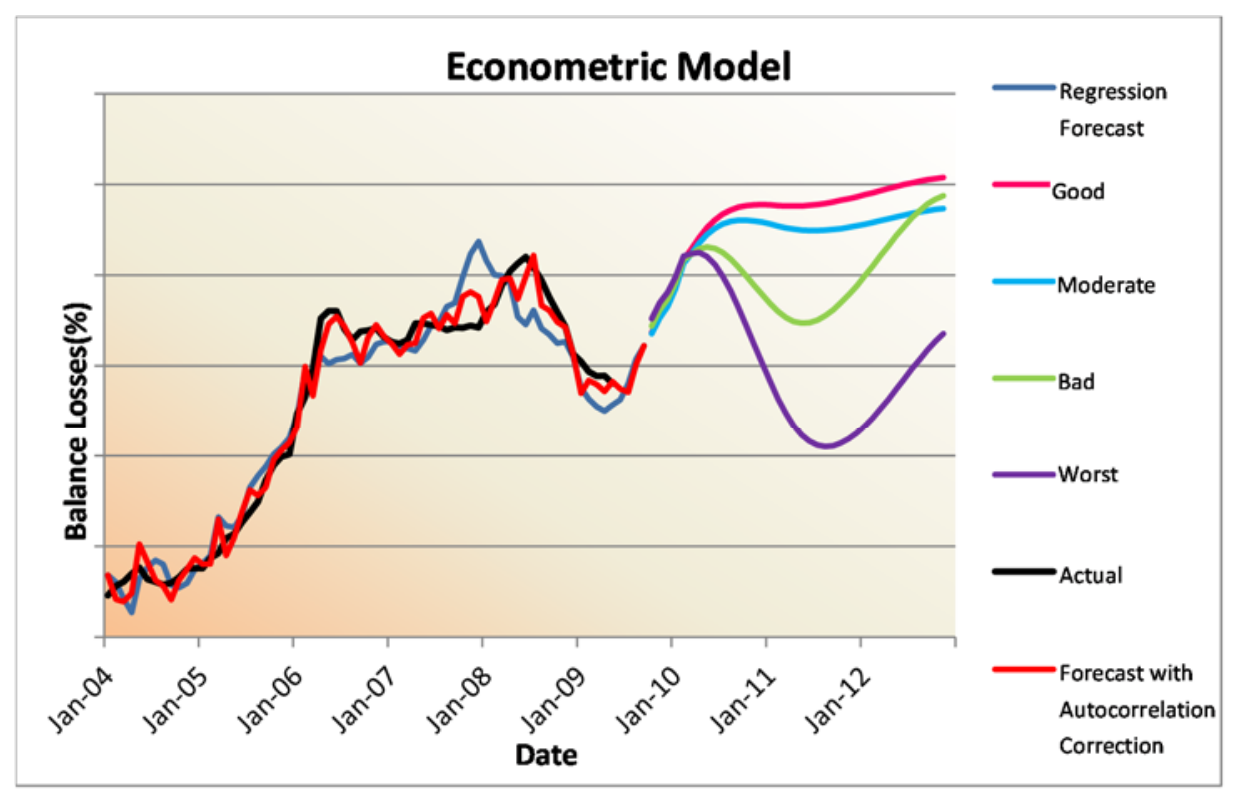

Figure 4: Basic regression Model with new GDP spline

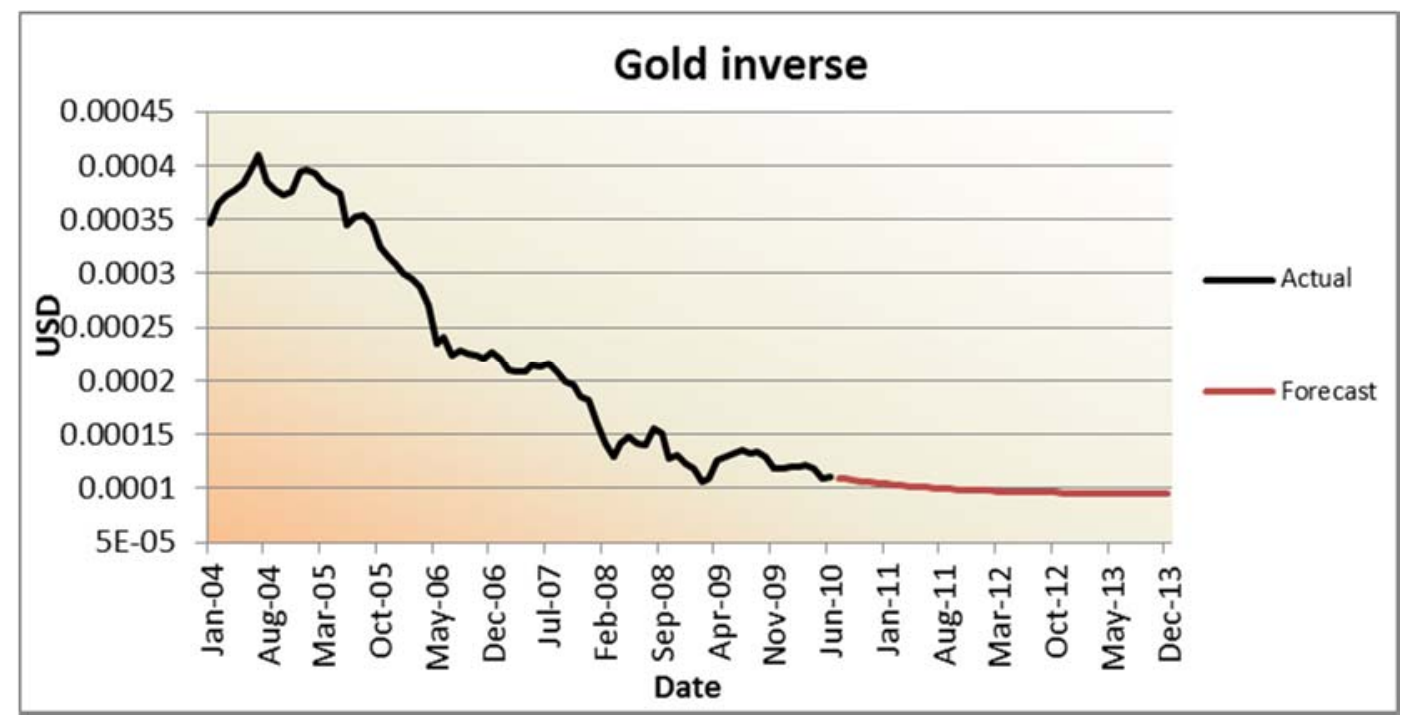

Figure 5a: Gold Inverse 


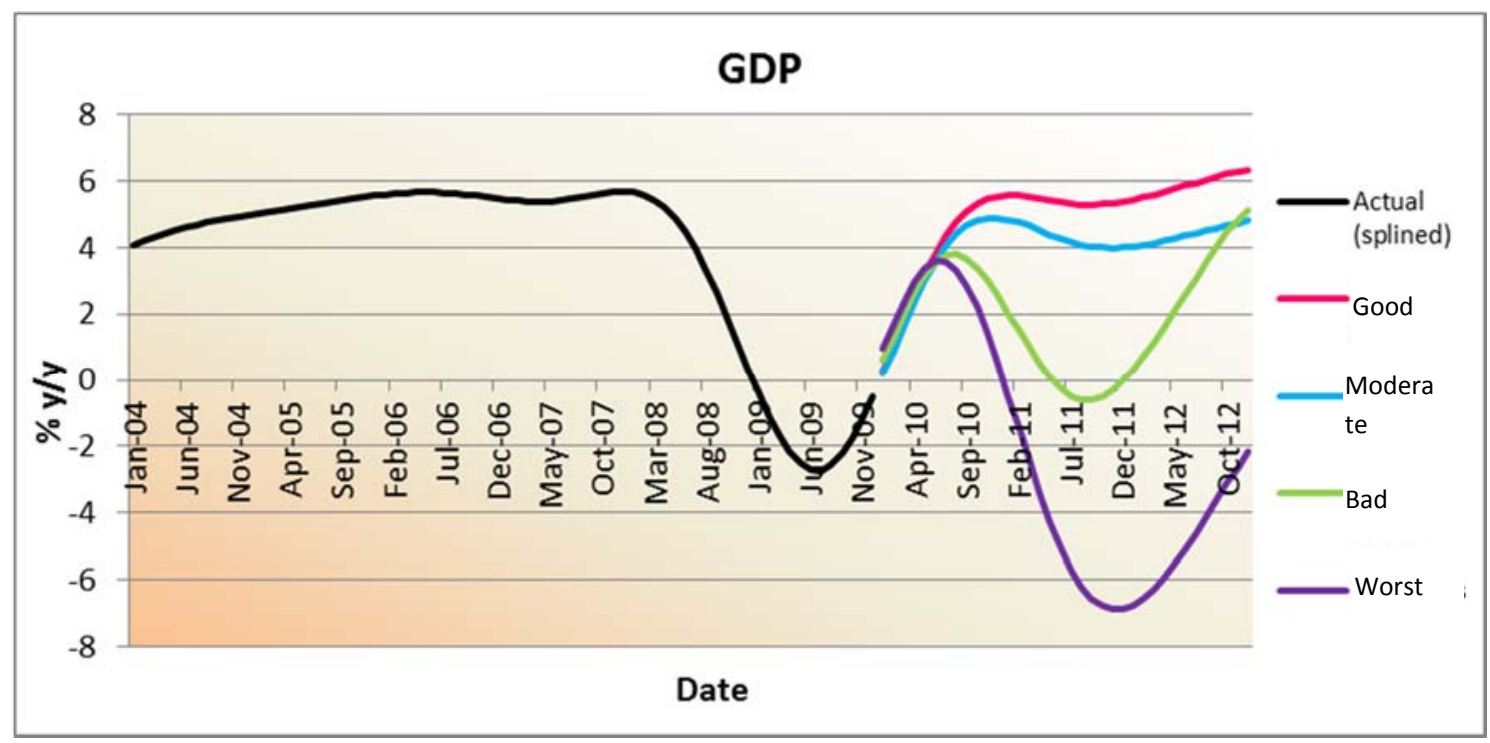

Figure 5b: GDP (newly splined)

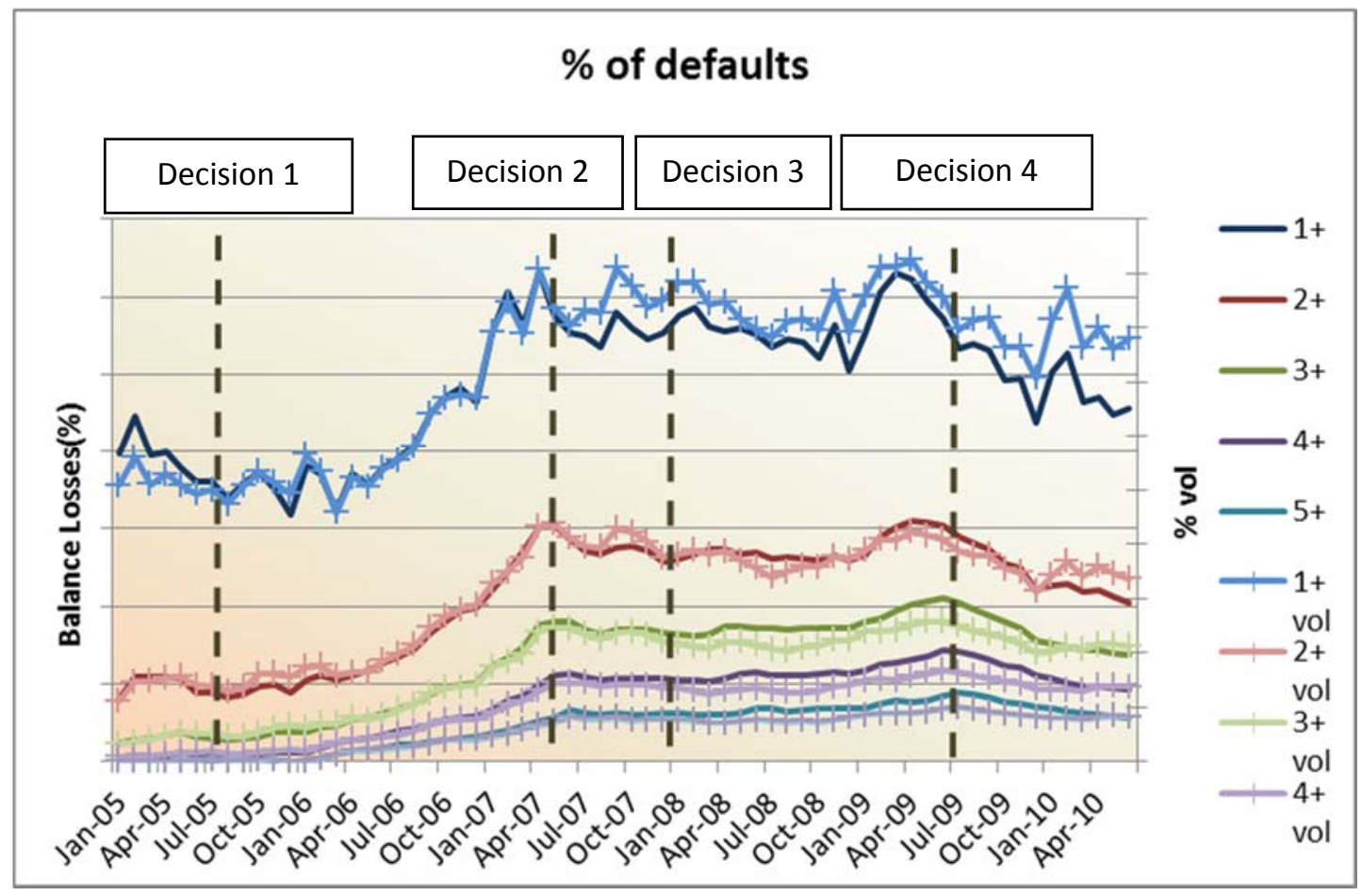

Figure 6: Timings of decisions made by lender 


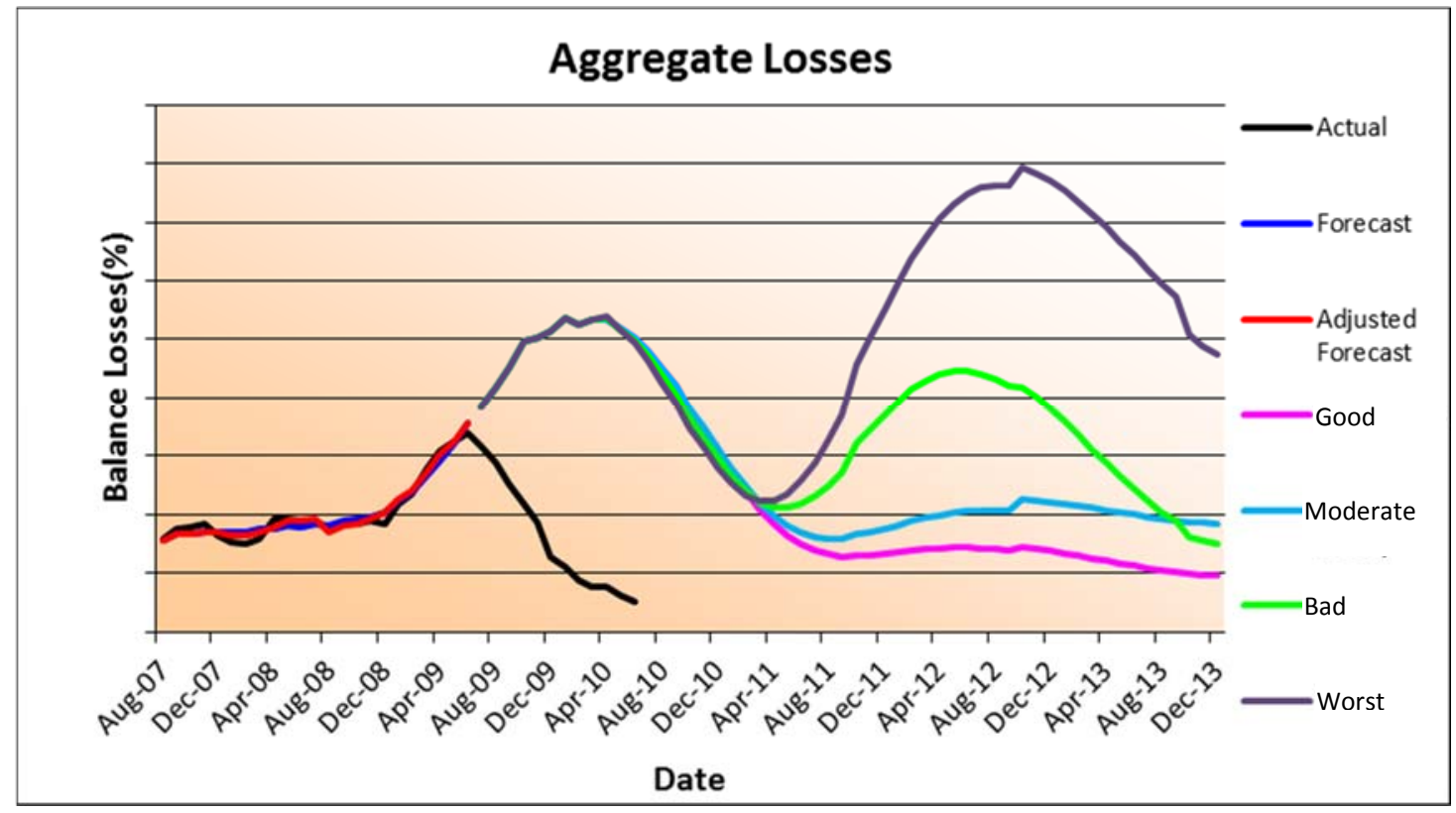

Figure 7: Hybrid Aggregate Model forecasted losses

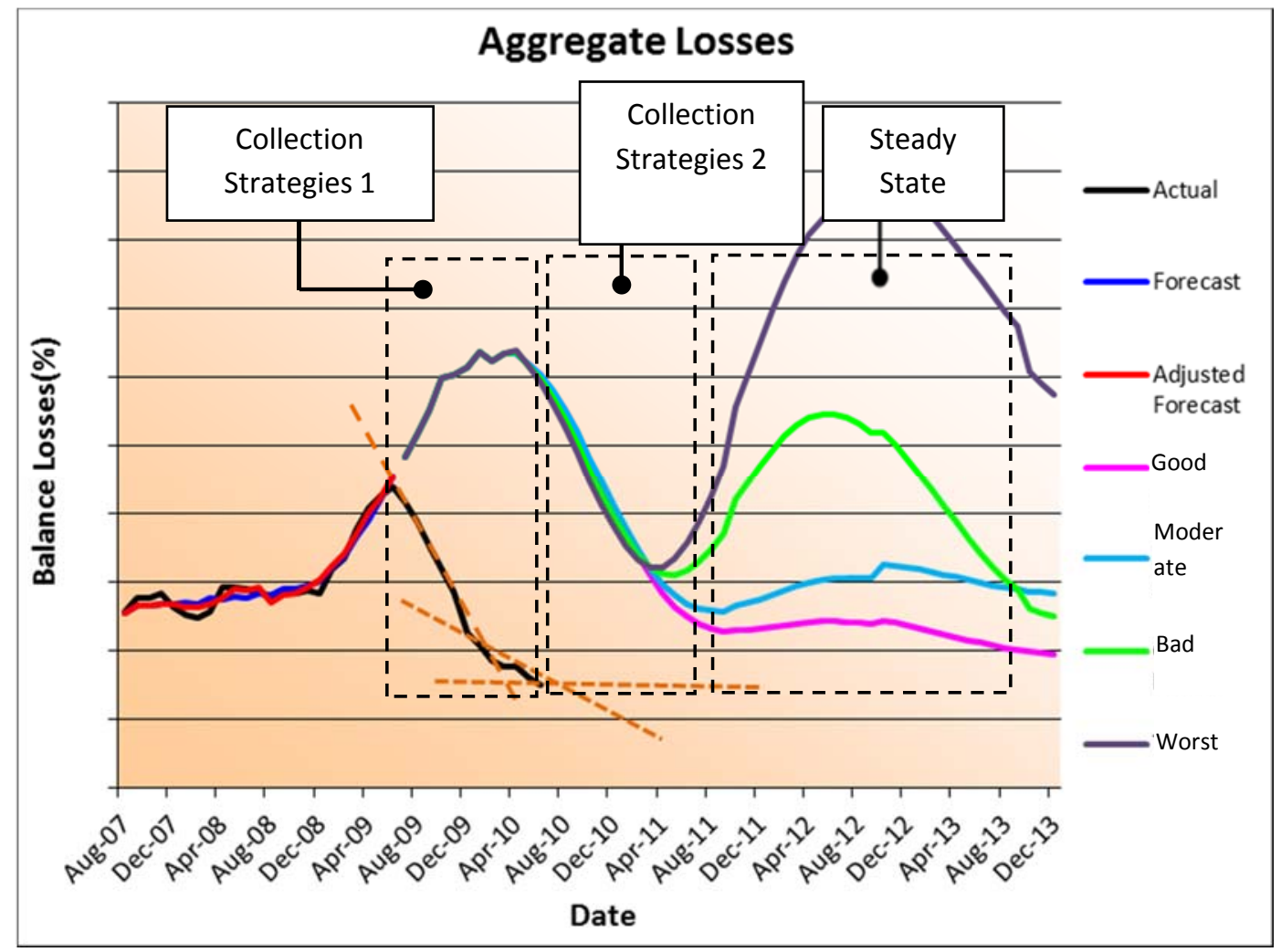

Figure 8a: Timings of decisions 


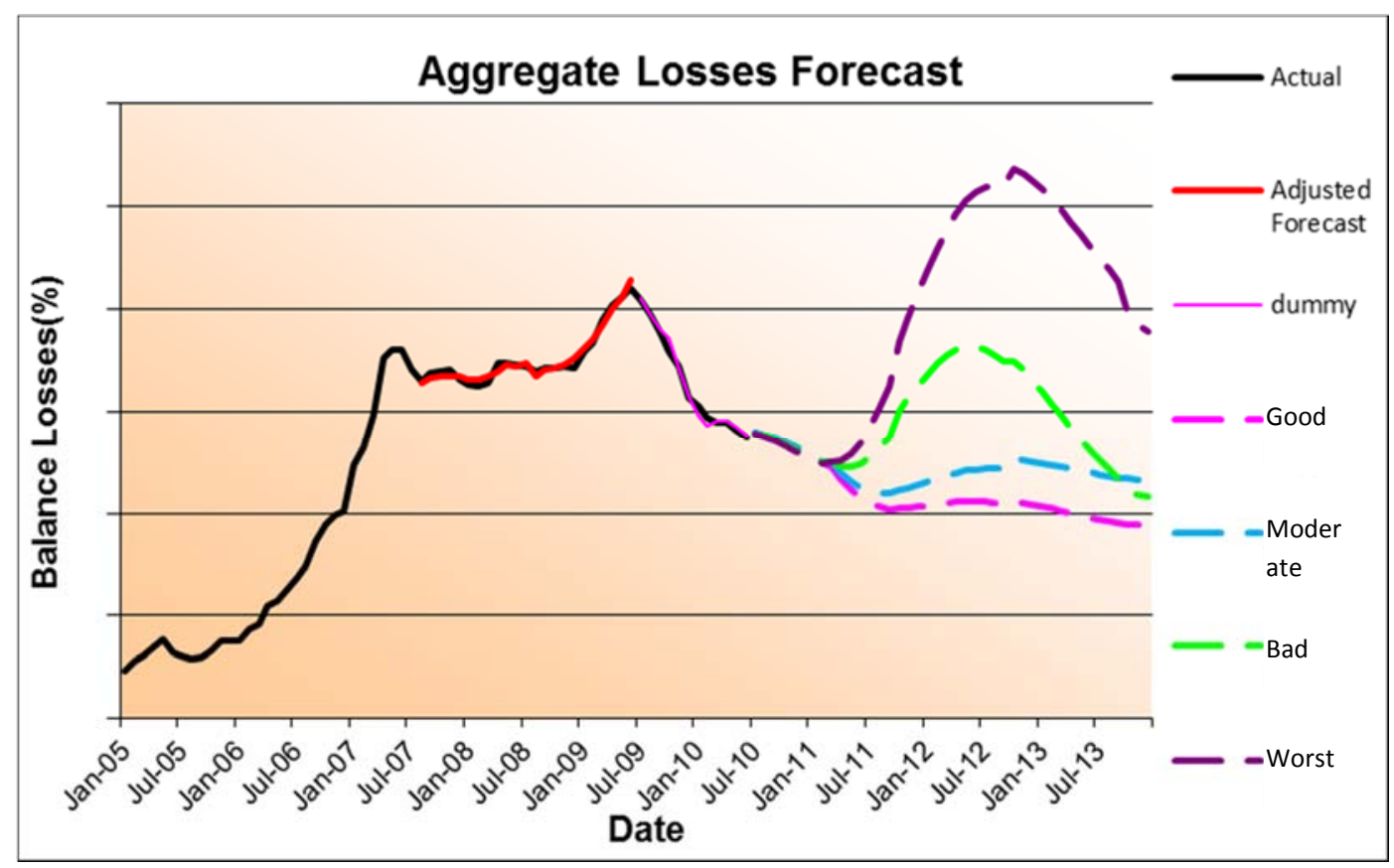

Figure 8b: Forecast of Hybrid regression based aggregate Model

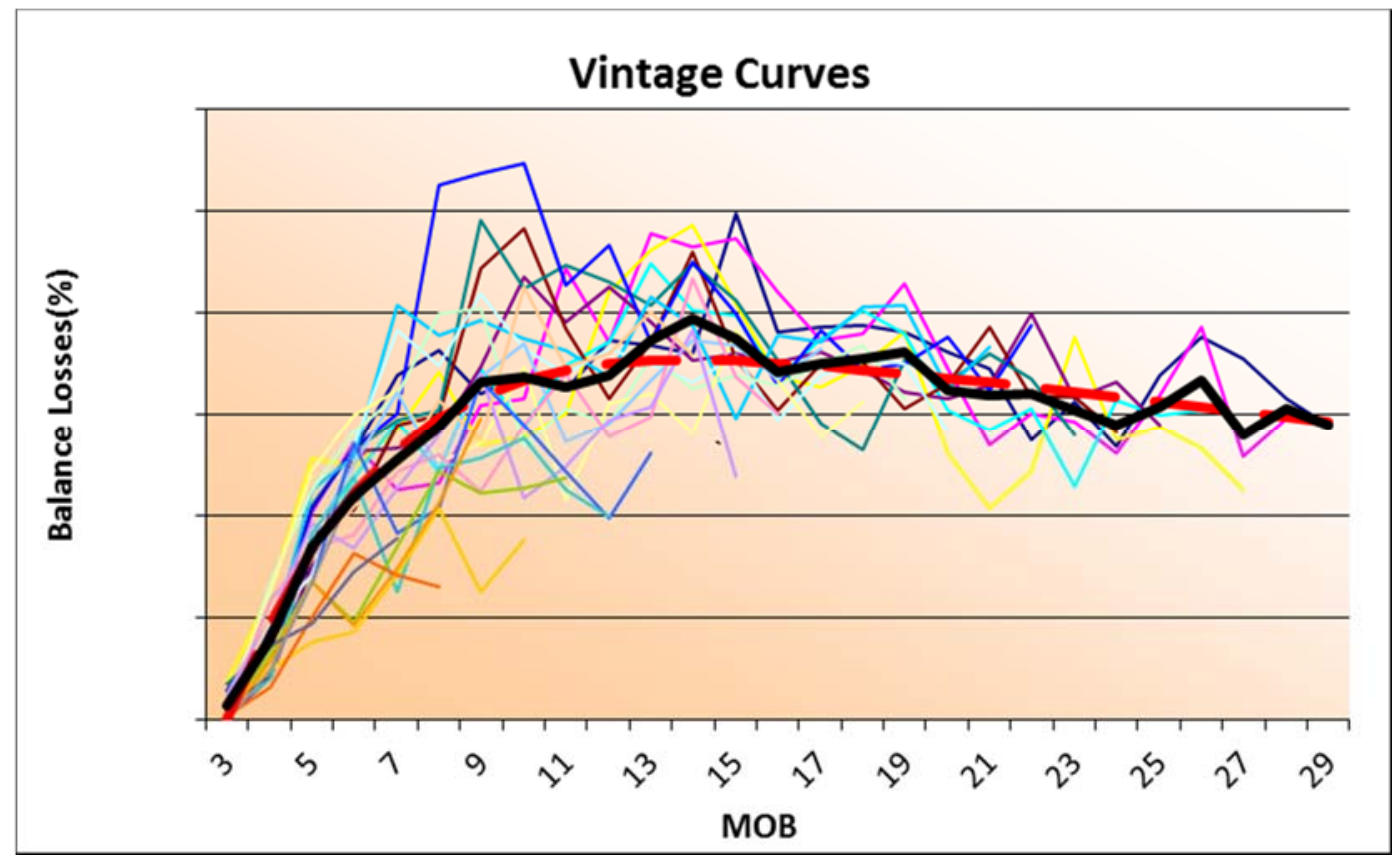

Figure 9: Average and each vintages' Maturation Curve 


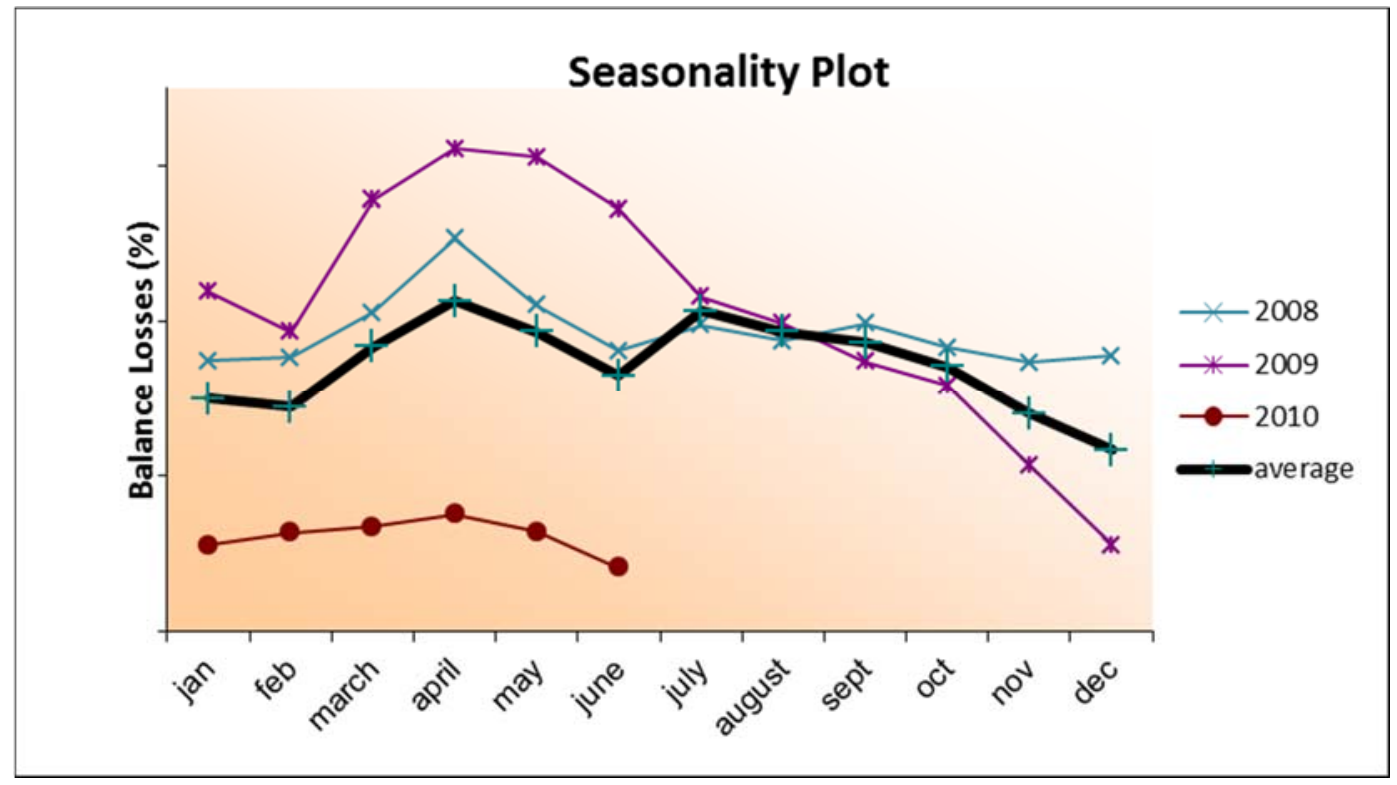

Figure 10: Impact of seasonality 


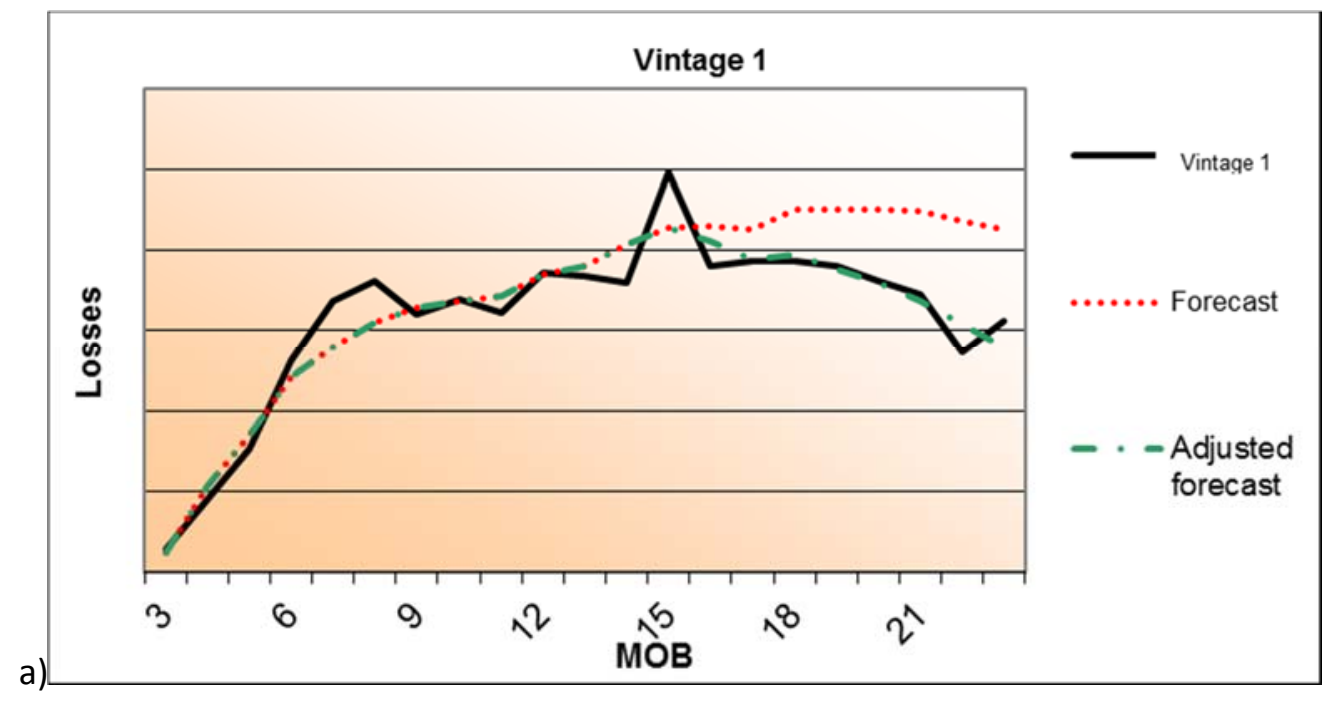

b)
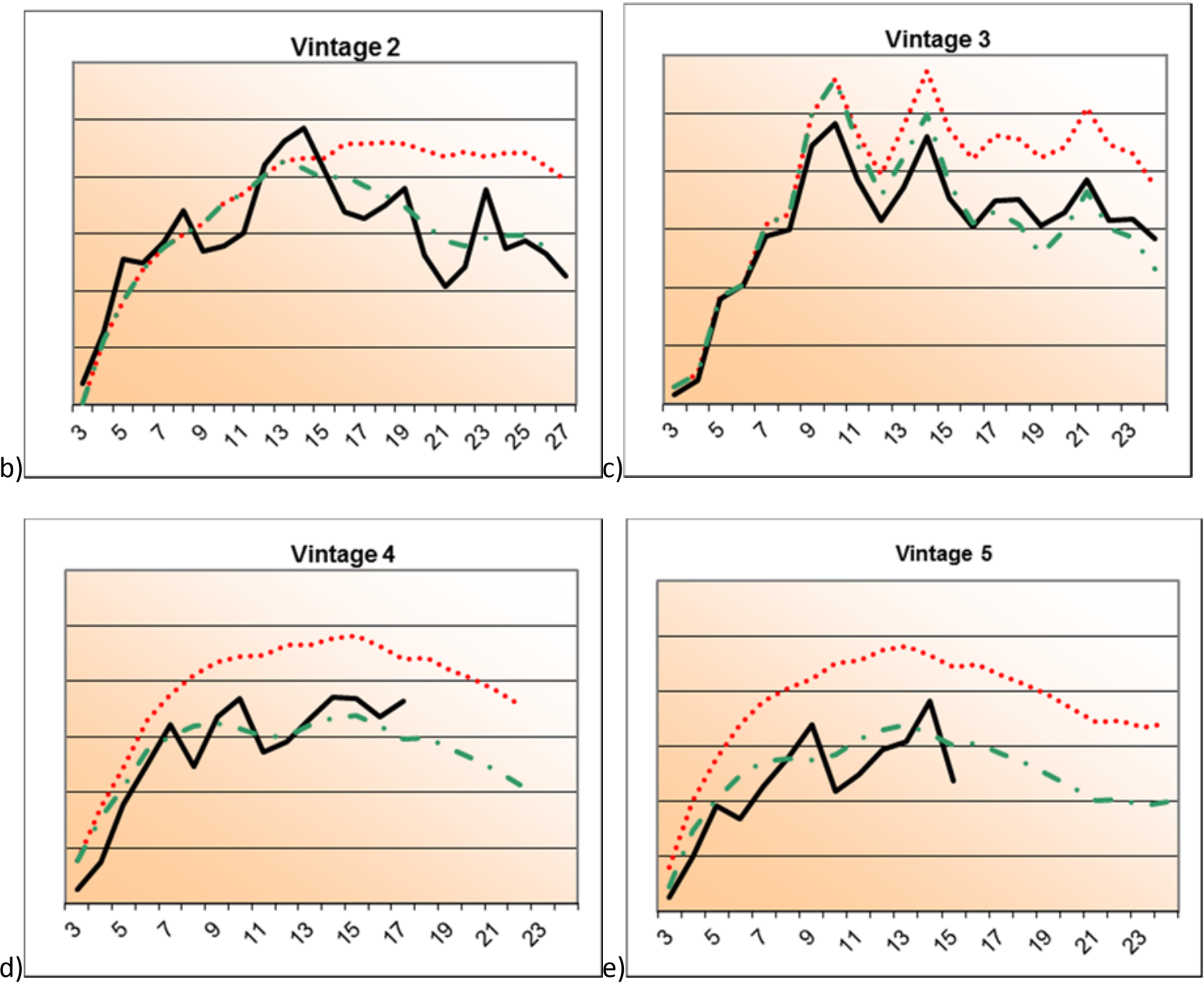

Figure 11: Actual, Forecast, Adjusted Forecast of some vintages (these are vintage in Jan-08, Mar-08, Jun-08, Jan09, Mar-09) 